HORTA. L • La construcción estética del sujeto popular en el documental "Mimbre" (1957) de Sergio Bravo

\title{
La construcción estética del sujeto popular en el documental "Mimbre" (1957) de Sergio Bravo ${ }^{1}$
}

The aesthetic construction of the popular subject in the documentary "Mimbre" (1957) by Sergio

Bravo

Luis Horta ${ }^{2}$

UNIVERSIDAD DE CHILE

Resumen. En el marco de los estudios del cine chileno, que sitúan la representación del sujeto popular como epicentro de un trabajo estético de indagación, este artículo busca analizar las operaciones cinematográficas y estéticas que emplea el cineasta Sergio Bravo en su documental "Mimbre" (1957), en el cual trata de establecer un lenguaje asociado a una idea de identidad local. El análisis de la obra nos indica un contrapunto entre sujeto popular y vanguardias artísticas. Toma como motivo central la cotidianeidad del artesano Alfredo Manzano, "Manzanito", planteando una subversión visual a la idea de realidad chilena propuesta por el cine del periodo. Como conclusión, el trabajo de Sergio Bravo no solo resulta rupturista en la forma, sino en la conciencia política del rol de las imágenes en un proceso que asume la construcción de un lenguaje propio en un periodo que evidencia aperturas hacia el arte popular.

Palabras clave: Cine chileno; Documental; Sergio Bravo; Mimbre; Manzanito; Arte Popular.

\begin{abstract}
In the framework of the Chilean cinema studies, which place the representation of the popular subject as the epicenter of an aesthetic investigation work, this article seeks to analyze the cinematographic and aesthetic operations that the filmmaker Sergio Bravo uses in his documentary "Mimbre" (1957), in which he tries to establish a language associated with an idea of local identity. The analysis of the work indicates a counterpoint between popular subject and artistic avant-garde. It takes as a central motif the daily life of the artisan Alfredo Manzano, "Manzanito", posing a visual subversion to the idea of Chilean reality proposed by the cinema of the period. In conclusion, Sergio Bravo's work is not only disruptive in form, but also in the political conscience of the role of images in a process that assumes the construction of a language of its own in a period that shows openness towards popular art.
\end{abstract}

Key Words. Chilean cinema; Documentary film; Sergio Bravo; Wicker; Manzanito; Popular art.

\footnotetext{
${ }^{1}$ Los resultados de este trabajo forman parte de una investigación desarrollada en el marco del curso Antropología de la Imagen, coordinado por la Profesora Paulina Faba del Programa Magíster en Teoría e Historia del Arte, Facultad de Artes, Universidad de Chile.

${ }^{2}$ Realizador de Cine y Televisión. Universidad de las Artes y las Ciencias Sociales ARCIS.
} 


\section{Introducción: las disputas por el pueblo}

Sergio Bravo Ramos (San Antonio, 1927) ha sido considerado, en diversas investigaciones, como un precursor de la renovación del cine chileno de los años cincuenta y sesenta (Mouesca, 1988; Corro, et al., 2007; Stange y Salinas, 2008; Ruffinelli, 2012). Su serie de documentales "Mimbre" (1957), "Trilla” (1958), "Día de Organillos" (1959) y "Láminas de Almahue" (1962) incorpora prácticas narrativas que para el cine chileno resultan innovadoras, pues colocan la representación del sujeto popular como epicentro de un trabajo estético de indagación, que podría emparentarse con la poesía de Pablo Neruda, la obra plástica de José Venturelli o la música de Violeta Parra, entre otros. Bravo, al igual que ellos, se interesa en captar una realidad local que, consideraba, mantenía ajena a la pantalla cinematográfica lo que él denomina como la riqueza cultural de Chile (Bravo Ramos 38). Subordinado mayoritariamente al cine industrial norteamericano, el cine chileno del periodo se encontraba fuertemente influenciado por la cultura de masas y la entretención. Bravo rememora esto en una entrevista realizada por la historiadora Jacqueline Mouesca para la revista Araucaria: "Era una época en que estaba en plena moda el "star system", y en que la única revista chilena de cine era Ecran, dirigida por doña María Romero, que publicaba en ella críticas firmadas con su nombre que eran simplemente copias de las críticas de la revista norteamericana Variety" (Mouesca 103).

En palabras de Carlos Ossandón y Eduardo Santa Cruz: "la industria cultural es precisamente cotidianizar la modernidad, es decir, naturalizarla" (23), lo cual no hace sino tensionar las relaciones iconográficas que se producen entre una sociedad mayoritariamente agro productora, como la chilena. Los modelos de representación que instala la industria del cine son consumidos masivamente por la población. En cambio, un cine de carácter artístico o de exploraciones estéticas no contaba con un desarrollo sistemático en el país ${ }^{3}$. Para Carlos Ossa Swars:

Las naciones oprimidas por imágenes hegemónicas reciben lo extraño y descontextualizado como un modelo a seguir, pero es imposible recibir la mirada del otro cuando la propia ha sido negada, sepultada o suspendida para aceptar una fuerza visual que inventa pueblos para invisibilizar pueblos" (154-5).

La obra de Sergio Bravo instala operaciones estéticas innovadoras dentro de las prácticas del cine chileno del periodo, lo que abre el campo del cine de ensayo, en el cual la sensibilidad sobre el mundo popular queda evidenciada por los dispositivos temáticos que instala. Entre ellos, un artesano del mimbre, el organillero y su recorrido por las calles de Santiago, el carretonero, el trabajador del aseo, los niños de la calle, la trilla o los campesinos de Almahue. Su propuesta es absolutamente subjetiva y con vocación por el acercamiento a la raíz identitaria por medio de

\footnotetext{
${ }^{3}$ Un antecedente puede ser la obra documental de Armando Rojas Castro (1896-1968), documentalista con formación en Alemania, que desarrolló películas etnográficas y educativas con fuerte énfasis en la estética. Para más información: Álvarez, et al.: "El cine en el aula: el Instituto de Cinematografía Educativa de la Universidad de Chile (1929 - 1948)"

en Cuadernos Chilenos de Historia de la Educación $N^{\circ} 2,2014 . \quad$ Disponible en: http://historiadelaeducacion.cl/index.php/CCHE/article/view/80
} 
HORTA. L • La construcción estética del sujeto popular en el documental "Mimbre" (1957) de Sergio Bravo

imágenes y atmósferas que elaboran un concepto abstracto de lo nacional y lo popular. Se emplea un medio moderno, como el cine, pero de forma artesanal, debido a su factura, al tratarse de documentales realizados con cámaras portátiles de $16 \mathrm{~mm}$, sin sonido directo, con un proceso de montaje técnicamente rústico o la distribución, principalmente, en espacios universitarios. Esta propuesta se opone a los lineamientos tradicionales del cine chileno del periodo, que en palabras de Carlos Ossa Coo, se encontraba sumido "en pleno período de profunda crisis de la industria" (68). La inquietud de Bravo, enfocada en una supuesta recuperación de la cultura popular, además de deshacerse de esta imagen representacional pre construida por el mercado y las industrias culturales, desecha las prácticas del rodaje, montaje y exhibición industrial, operando en equipos reducidos de colaboradores, lo que le permite tener autonomía en la toma de decisiones artísticas de la película ${ }^{4}$.

Al hacer interactuar el registro con una construcción narrativa estilizada y poética de la condición cultural de las clases proletarias chilenas, Sergio Bravo presupone la posibilidad de abordar el cine como una construcción autónoma a los designios del mercado, donde el uso de la voz, la luz, el montaje y la disposición de elementos dentro del cuadro lo sitúan como pionero en la exploración de una subjetividad identitaria. A partir de lo anterior, surge el objetivo de esta investigación: analizar las operaciones cinematográficas y estéticas que emplea el cineasta Sergio Bravo en su documental "Mimbre".

\section{La obra de Sergio Bravo: influencias y tensiones}

La formación de Sergio Bravo como arquitecto en la Universidad de Chile en la década de los cincuenta permite entender cierto acercamiento del autor a la problematización del paisaje y la articulación por medio del montaje de una representación visual del espacio. Esto se puede contextualizar en una academia adscrita a un proceso de transformación, donde las tendencias de vanguardia sugieren una aproximación artística al empleo de determinados recursos:

La verdad es que yo me siento tributario del clima intelectual de la post-guerra. Hice mis estudios secundarios en pleno período de la Segunda Guerra Mundial, y cuando, después, llegué a la Facultad de Arquitectura, las ideas antifascistas eran el caldo de cultivo de múltiples impulsos de cambio. En la Universidad se vivía un período de plena efervescencia por la Reforma, donde entraban todo tipo de iniciativas renovadoras y de tentativas de experimentación. Se planteaban todos los problemas

\footnotetext{
4 Entre los técnicos colaboradores habituales de Sergio Bravo en este periodo se encuentran su esposa, Sonia Salgado, y el cineasta Pedro Chaskel, el cual iniciará posteriormente una obra documental fundamental en la historia del cine chileno. También participaron en fotografía y cámara Daniel Urria y Enrique Rodríguez. A ellos se deben sumar otros intelectuales del periodo, quienes realizaron textos o música para sus películas, entre ellos los escritores Francisco Coloane y Volodia Teitelboim, los poetas Pablo Neruda y Efraín Barquero, los músicos Violeta Parra y Gustavo Becerra. Para más información ver: Bravo Ramos, Sergio. Reiterando Afanes, autoedición, 2019.
} 
de la estética arquitectónica; pero, además, estaban en cuestión todos los problemas

ligados a la cultura chilena (Mouesca 102-3).

Una de las principales influencias de Bravo durante este periodo estaría en una corriente artística de vanguardia como la Bauhaus, a partir del taller Análisis Arquitectural, que en 1946 comienza a impartir el húngaro Tibor Weiner, quien había adscrito a esta corriente. Introduce numerosas innovaciones en el contexto de reformas de la carrera e influenciará los procesos de transformación de esta disciplina en el país: "Según el testimonio de los ex alumnos, el taller de análisis arquitectural era un gran cambio en relación con lo que se había enseñado antes de la reforma en la escuela, ya que incorporaba la realidad de los programas, consideraba la escala humana y la relación de la arquitectura con el medio ambiente en el cual se insertaba" (Talensky 68). Estos aspectos serán determinantes en la exploración sobre una identidad chilena a partir de la subjetividad popular, donde el paisaje juega un rol fundamental en cuanto narración. El acercamiento al cine de Bravo propone un relato visual donde las formas básicas y su distribución en el cuadro confluyen en una representación formalista del paisaje popular.

Sin embargo, también sus primeros acercamientos a la cinematografía están determinados por su participación en el Cine Club Universitario, instancia fundada en 1954, que deriva de los vanguardistas franceses, quienes en la década del veinte subvierten el acto tradicional de ver cine reducido a objetivos comerciales, para proyectar a cambio obras de calidad artística acompañadas de un Cine Foro al final de la función. En este contexto, se reafirma la intención por articular un lenguaje cinematográfico que surja a partir de una idea de la cultura chilena, pero desde el cine: "Nosotros queríamos apostar a un nuevo lenguaje, independizarnos totalmente de lo que veíamos como cine oficial chileno" (Mouesca 67). La formación de Bravo como cineclubista le permite acceder a la diversidad del cine, entre ellas el realismo poético francés, las corrientes del documentalismo soviético e inglés o el neorrealismo italiano, los que también señala como parte de su formación. Sin embargo, el foco estará en la relevancia que le da al "imperativo de valorar lo esencial de una vivencia en su contexto patrimonial comunitario" (Bravo Ramos 27), lo cual le permite vincularse con la realidad local a partir de un medio moderno como el cine, entendiéndolo como parte de una modernidad de la cual surge la voluntad de construir visualmente la idea de pueblo según Gilles Deleuze: "Que falta el pueblo quiere decir que esta afinidad fundamental entre la obra de arte y un pueblo que aún no existe nunca será algo claro. No hay obra de arte que no apele a un pueblo que aún no existe" ("La imagen-tiempo", 2016: 290). Bravo, al tomar como referente a corrientes fílmicas exploratorias, también evidencia una toma de consciencia respecto al rol de la imagen en su relación con la identidad cultural chilena, lo cual deviene en una política de las imágenes cuyo punto de vista se sitúa en construir visualmente un pueblo claramente definido por su clase social y, hasta ese entonces, solamente abordado por el cine chileno en torno a los arquetipos de la industria. En esta transformación, es preponderante la influencia de cineastas como John Grierson o Dziga Vertov, quienes entienden la obra como parte de una aprehensión poética de la realidad, estrategias empleadas en los relatos que posteriormente desarrollará Bravo y que veremos más adelante.

Pasar de espectador a realizador será el paso siguiente de Sergio Bravo. En 1957 filma un inacabado documental sobre el Cerro Santa Lucía. Ese mismo año inicia la filmación en que registra el proceso de creación de figuras de mimbre por parte del artesano Alfredo Manzano "Manzanito", en su taller ubicado en la calle Abtao 275, en la comuna de Quinta Normal. También en ese año, Bravo funda y dirige el Centro de Cine Experimental, un núcleo de creación fílmica independiente, aunque recibe el auspicio de la Secretaría General de la Universidad de Chile por 
HORTA. L • La construcción estética del sujeto popular en el documental "Mimbre" (1957) de Sergio Bravo

medio de Álvaro Bunster, quien le proporcionará espacio físico para albergar las oficinas y recursos para sonorizar sus primeras películas; cortometrajes que serán alabados en términos estéticos por la crítica del periodo, aun cuando circulan entre un público reducido ${ }^{5}$. La idea de un rescate cultural despojado de los maniqueísmos comerciales se evidencia también en el proyecto de restauración de la película silente "El Húsar de la Muerte", realizada en 1925 por el poeta y actor Pedro Sienna y que, gracias a su rescate, permite establecer un hilo de pertenencia con un cierto tipo de cine anterior ${ }^{6}$.

En el año 1960, la Universidad de Chile incorpora como parte de sus unidades a Cine Experimental, formalizando su apoyo a la idea original de Sergio Bravo dentro del espacio académico, lo que genera un departamento de creación cinematográfica no comercial. Esta unidad recibe la visita del documentalista Joris Ivens, en el año 1962, lo que significa un respaldo a la labor de la creación cinematográfica dentro del plantel estatal, pero además una posibilidad cierta de realización junto a un autor de primera línea a nivel mundial, quien replicó en Chile su idea del taller-escuela filmando el documental "A Valparaíso", en el cual Bravo trabajó como asistente de dirección y productor. A partir de esta relación, Bravo también ejerce como montajista de otro film de Ivens, "El tren de la Victoria", sobre la campaña presidencial de Salvador Allende en 1964. En este periodo filma "Las Banderas del pueblo" (1960) y "Láminas de Almahue" (1962). En 1964, después de filmar el documental "Parkinsonismo y Cirujía" (1964), cierra una primera etapa, luego de que no le es renovado su convenio a honorarios en la Universidad de Chile. Debido a esto, y porque retoma su profesión de arquitecto, disminuye su producción. Volverá a la realización documental recién durante los años de la dictadura, cuando filma dos documentales: sobre el escultor Samuel Román en 1978 y el largometraje "No eran nadie" en 1979. En 1982, termina en el exilio. A su retorno a Chile, en la década de los noventa, realiza "Aquel Nguillatún”, documental etnográfico que incorpora registros realizados durante el terremoto de Valdivia de 1960 a comunidades mapuches, y "Pan Minero" (2007), sobre la comuna minera de Lota.

\section{Mimbre: hacia una poética del arte popular}

Planteado como una crónica doméstica, "Mimbre" aborda un mundo cotidiano que deviene poesía, en el cual la práctica de un artesano constituye un retrato abstracto de un oficio, hasta ese instante, nunca abordado por el cine chileno. La elección del tema, fundamental para entender la idea de la subversión del canon, opta por relevar al sujeto popular a una condición estética y, en este caso, la actividad artesanal pasa a constituir el epicentro de un relato social de la cultura nacional. Bravo establece el retrato de un trabajador popular, lo cual le permita generar una operación identitaria con el público a través del reconocimiento de un grado de pertenencia. Esto último, que resulta difícil de cotejar debido a la ausencia de fuentes documentales que recojan el impacto de la obra en sus públicos, será también el intento por abordar desde la práctica documentalista, un ejercicio de exploraciones sobre la realidad social que, a la vez, es la subjetivación de una comunidad no

${ }^{5}$ Si bien no existe documentación al respecto, aparentemente las películas de Sergio Bravo tienen una primera exhibición pública en el mes de junio de 1959 en la Universidad de Chile. Su producción en 16mm hacía que solo tuviesen circulación en centros culturales, universidades e instancias informales. Para más información: Vega, Alicia. "Itinerario del cine documental chileno 1900-1990". Universidad Alberto Hurtado, 2006.

${ }^{6}$ Sobre su recuperación: Horta, Luis. "La Historia del Húsar de la Muerte" en Santa Cruz y Barril (eds.) "El cine que fue: 100 años de cine chileno", editorial Arcis, 2011. REVISAR ESTE INTERLINEADO Y COLOR DE FUENTE 
representada. Es una intimidad delimitada por el hacer, práctica humana en que la artesanía deviene poesía del cotidiano.

La presentación, con un texto introductorio, señala que la película abordará "impresiones visuales" (1'08'), tomando distancia de un conflicto central y situando el carácter subjetivo del cineasta frente a la realidad. La película, con diez minutos de duración y acompañada de la música de Violeta Parra como banda sonora, consta de ochenta y cinco planos que, para este trabajo, hemos dividido en seis secciones. La primera es una suerte de presentación del personaje adosado al mimbre; la segunda es la construcción de objetos presentada por medio de numerosos planos detalles y énfasis en la abstracción visual; la tercera se centra en construir una especie de sinfonía de objetos que son mostrados en primeros planos con una composición no expositiva; la cuarta es la conjunción de forma, espacio y contexto, incorporando el plano detalle de una niña y abstracciones visuales; la quinta es nuevamente una especie de sinfonía, pero con objetos que simulan cobrar vida, tanto por el movimiento de cámara, como de los niños que los emplean de juguete; la sexta, es el epílogo que muestra las mujeres de la casa y al artesano, en el taller, mezclándose vida íntima y espacio de trabajo.

Al emplear recursos mínimos, como una cámara de $16 \mathrm{~mm}$, película en blanco y negro reversible, un equipo técnico de dos personas y solamente luz natural, el retrato del trabajo de "Manzanito" y su empleo de las varillas de mimbre expone la sensibilidad en la operación cinematográfica en que la cámara aborda las materias primas como un canalizador de la particularidad lumínica en un mundo íntimo, el de la creación, en coherencia con la estructura de un relato fragmentado, que enfatiza las abstracciones por medio de sesenta y dos primeros planos o planos detalle, lo cual da cuenta de una clara intención por construir un mundo hermético, un universo en sí mismo. Esta excepcionalidad del universo retratado tiene la particularidad de ser un espacio amplio en sus proyecciones fuera de campo, haciendo elocuente que este mecanismo representacional es alegórico y no intenta registrar de manera informativa la tarea del artesano. Solo hacia el final veremos un plano abierto (9'23'), empleado como recurso netamente plástico en el cual se expone por única vez al artesano y su espacio, el taller, reafirmando los elementos composicionales que Bravo ha ya desarrollado a lo largo de la película.

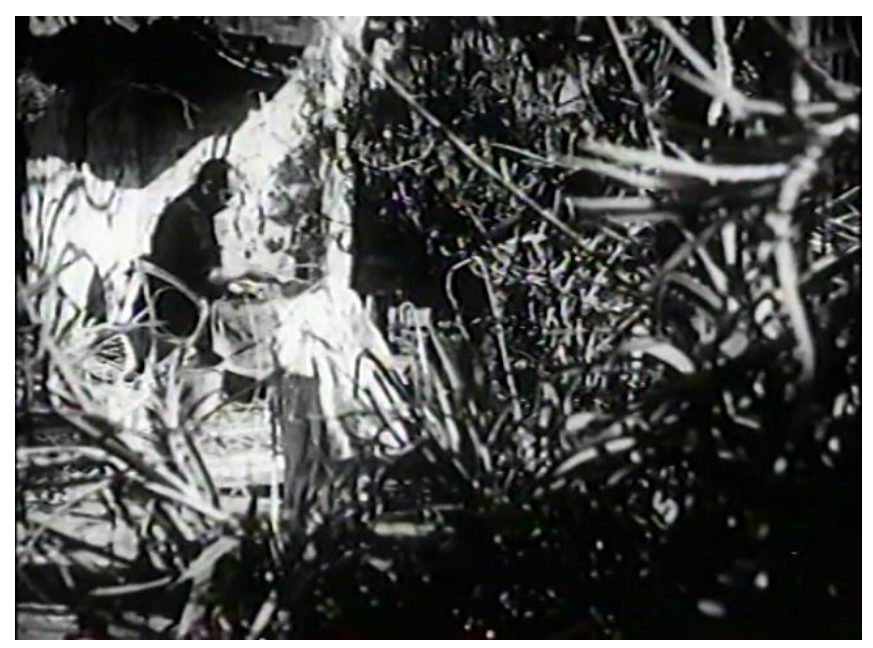

Figura 1

El artesano Alfredo Manzano, "Manzanito”, en su taller ubicado en la comuna de Quinta Normal. Es el único plano general de la película "Mimbre" (Sergio Bravo 1957) 
HORTA. L • La construcción estética del sujeto popular en el documental "Mimbre" (1957) de Sergio Bravo

La estrategia de montaje en la presentación del personaje muestra un plano medio del artesano, para luego saltar a un plano detalle de sus manos y luego a las hebras del material, que se abalanzan hacia la cámara, lo que proporciona una composición indeterminada. Usa una estrategia similar al cine abstracto de Norman McLaren, particularmente en películas como "Spooky sports" (1940), "A phantasy in colors" (1949) o "Blinkity Blank" (1955), establecida como una abstracción de la realidad por medio del detalle, volúmenes y formas en movimiento, que permite entender el interés particular de Bravo por estetizar la subjetividad del artesano en operaciones cinematográficas de vanguardia, tales como la fragmentación del espacio y la representación de un tiempo dinámico, componiendo unidades narrativas que desarticulan una lectura informativa del lugar en que el personaje se desenvuelve. En "Mimbre", las líneas cruzan el cuadro para proponer una especie de entramado de materialidad y luz, intercalado en el montaje por aspectos singulares de la intimidad. Siguiendo a Gilles Deleuze, "por más que el cine nos acerque y nos aleje de las cosas, y nos haga girar alrededor de ellas, él suprime el anclaje del sujeto tanto como el horizonte del mundo, hasta el punto de sustituir las condiciones de la percepción natural por un saber implícito y una intencionalidad segunda" ( "La imagen-movimiento", 2018:88).

Esta operación parece testimoniar el modo en que "Manzanito" habita un espacio, sin separar el oficio, de sus prácticas cotidianas, lo cual es reforzado por la inserción de planos que muestran a un gato entre las varas de mimbre o a unos niños jugando con algunas de las piezas de cestería. En palabras de Gastón Bachelard: "hay que comprender que en la miniatura los valores se condensan y se enriquecen. No basta una dialéctica platónica de lo grande y lo pequeño para conocer las virtudes dinámicas de la miniatura. Hay que rebasar la lógica para vivir lo grande que existe dentro de lo pequeño (198).

Se trata de una introducción formalista al mundo de la cultura popular, generándose en esta interacción una premisa de relato poético que discursivamente ataca las reglas de la semántica cinematográfica tradicional. La escala de planos que emplea Bravo le permite acercarse a las texturas y los volúmenes, en una subversión visual a la idea de realidad propuesta por el cine chileno del periodo. En "Mimbre", la luz parece jugar un rol preponderante en la representación espacial de una cultura autóctona. La dureza con que se imprimen los destellos de luz sobre la materia, o en la piel del artesano, parecen alimentar esta idea formalista de las abstracciones basadas en la geometría a partir de diversos elementos de la realidad, similar a lo que plantea una película como "Berlín, sinfonía de una gran ciudad" (Walter Ruttman 1927). En ella, a partir de una concepción visual abstracta y experimental, se intenta abordar la problematización estética del paisaje como instancia de apropiación de los sujetos. El formalismo en Bravo se acerca a esta idea en una secuencia iniciada en el minuto 5'11' 'y terminada en el 8'32', donde dos segmentos aluden al movimiento interno y externo de la imagen. Las alternancias de planos detalles de objetos de mimbre, en la primera, y los objetos que parecen cobrar vida a partir de una cámara que juguetea con los niños en el taller. Esta construcción permite abordar un universo en sus propias leyes y claves, pero que surge a partir de la construcción dada por el montaje, develando la influencia de la Bauhaus, en donde emergen proporciones provistas por la materialidad. En ambas, se evidencia el interés por construir, al interior de la obra, una determinada ordenación lógica que alude a la realidad por medio del encuadre, el movimiento y el montaje, donde la musicalidad es enunciada por el movimiento y sus formas, incluso al colocar la cámara al interior de un objeto de mimbre, para captar las luces y volúmenes en un lugar donde habitualmente el ojo humano no se ubica. Así, tanto la luz como el encuadre permiten abordar una idea de la identidad bajo una delimitación consciente de los fragmentos que constituyen un universo que abre posibilidades perceptivas en 
sus detalles, en las formas, que emergen por medio de la disposición de elementos ínfimos que se amplían por la ubicación de la cámara, el uso de la óptica y el encuadre.

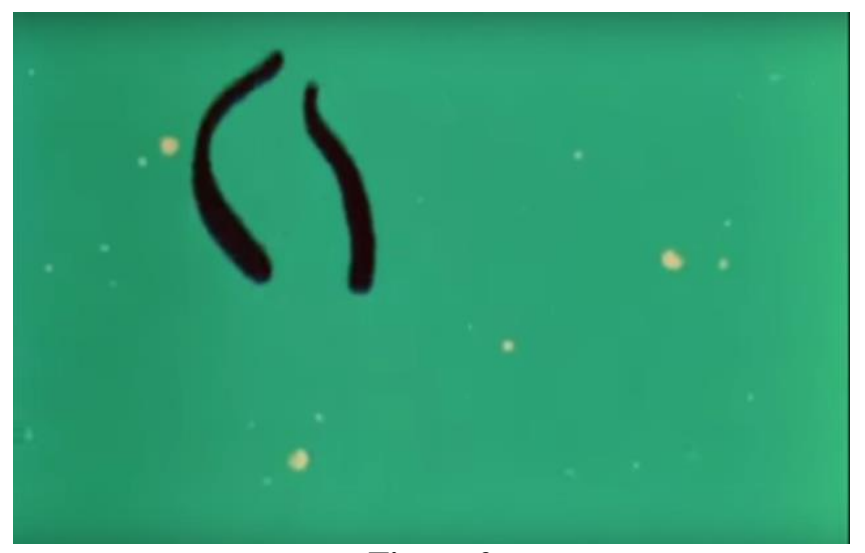

Figura 2

"Spooky sports" (Norman Mc Laren, 1940)

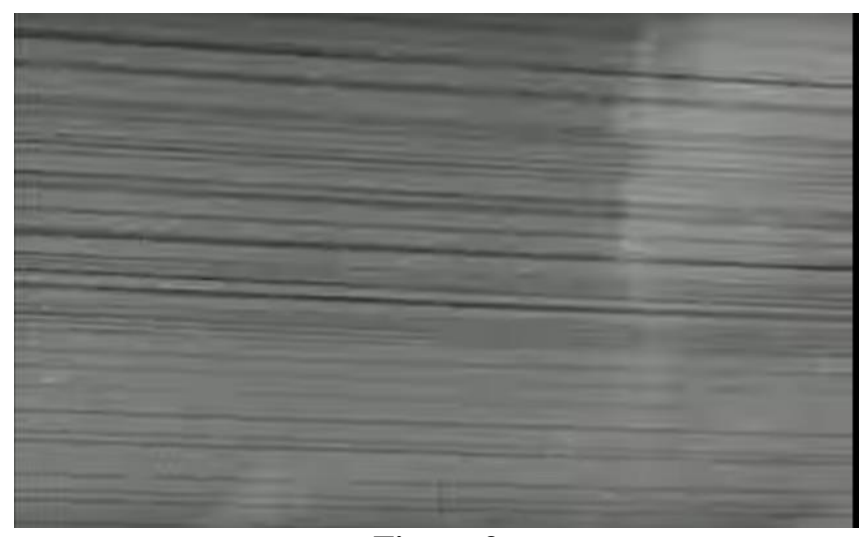

Figura 3

"Berlín, sinfonía de una ciudad” (Walter Ruttman, 1927)

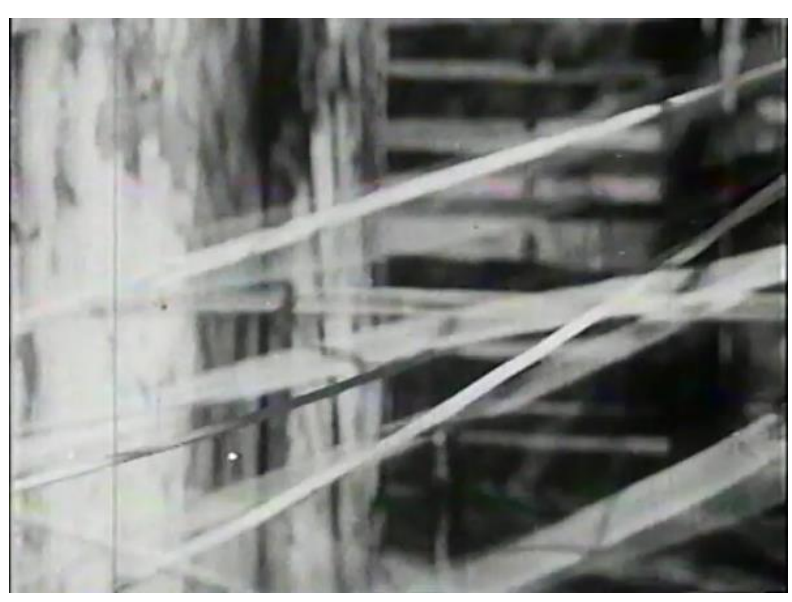

Figura 4

"Mimbre" (Sergio Bravo, 1957) 
HORTA. L • La construcción estética del sujeto popular en el documental "Mimbre" (1957) de Sergio Bravo

En este sentido, el montaje adquiere gran relevancia al proponer una fragmentación de las acciones simples, muy similar al documental canadiense "Corral" (Colin Low, 1954), que relata cómo un campesino ensilla a su caballo y arrea al ganado hacia un corral. En esta simple película, que gira narrativamente en torno a un hábito tradicional en los cowboys, también surgen símiles en la intención de construir un espacio exploratorio de la identidad, basándose en una representación minimalista del cotidiano contextualizado en la naturaleza, para plantear con ello un espacio metafórico de relaciones entre el sujeto y un entorno que deviene forma. El espacio poético constituye un elemento concreto, en la medida que se adosa al objeto documentado y permite entender la íntima relación entre espacio y prácticas del sujeto. Ambas películas se articulan sin voz en off, acompañado de musicalización en guitarra que parece conjeturar la activación de un espacio de sensibilidad por medio de un montaje y la sonoridad, que explota la riqueza estética de un hábitat condicionado por las labores del hombre en una especie de interrogación de la cámara hacia los objetos que componen este universo situado fuera de la modernidad.

El tratamiento pictórico que genera el movimiento de la cámara y el montaje, construye formas aleatorias que presuponen un constructo que intenta establecer un tiempo específico del mundo popular chileno. De acuerdo con lo anterior, el uso del primer plano también adquiere una connotación poética, al convertir el rostro o los pequeños gestos del artesano en gestos que hablan de su historicidad, situándolo como parte de procesos culturales que permiten entender la profundidad del tratamiento sobre la identidad que le interesa abordar a Bravo. Así, la primera parte de la película se acerca a las manos y a la técnica del oficio; mientras que en una segunda parte emerge el rostro, encuadrado permanentemente junto a la materia artesanal, proponiendo con ello una imagen indivisible entre sujeto y materia, resaltado y aumentado por la manera en que se incorporan las luces y sombras del taller. En ello, es fundamental el relato lumínico, que no solo contempla luces y sombras, ya que se configura a través de los volúmenes que construye en los objetos de mimbre. Esto permite acercarse también a una temporalidad local, dada por el empleo de la luz natural que manifiesta el paso del tiempo y que, en palabras de Jacques Aumont: "el tiempo ocular es, evidentemente, el de la exploración de la superficie de la imagen por parte del ojo" (62). Es un tiempo que se hace eterno, en la medida que la película se permite aprehender el momento efímero en su calidad poética y, por tanto, la imagen cinematográfica toma conciencia de sí misma para acercarse al sujeto perenne en una actividad, hasta ese instante, invisible en cuanto narrativa, donde el todo se confunde con una materialidad que emerge en una estructura de montaje tan orgánico como expresivo.

La abstracción que propone la fragmentación de un espacio y una acción se relaciona directamente con la forma artesanal en que se filma y edita la película, dado que Bravo reconoce que no contaba con infraestructura profesional y muchas veces se vio limitado a construir el relato de forma casi rudimentaria. Es similar a lo que sugiere Dziga Vertov, para quien el constructo se evidencia para entender que la organicidad está puesta de manifiesto en la obra, que debe "evidenciar la vida como tal" (63). En ello, "Mimbre" reconoce un claro acercamiento al mundo popular, no solamente en el formalismo en que construye el relato, sino que la ubicación de la cámara que prefigura un relato desde dentro de los acontecimientos, estratégicamente leyendo las acciones como parte de una metáfora visual en la que el espacio es denotado en un conjunto que solo existe en la narración, prescindiendo de planos referenciales o explicativos. Las figuras de mimbre se elevan a una significación abierta de la realidad del sujeto popular, ensimismado en sus prácticas y costumbres, y que, bajo la idea de las oposiciones que propone Sergei Eisenstein, está dado por la relación objeto-sujeto, planteando una mímesis entre materia y artesanía que aborda directamente el encuentro con la raíz y la identidad de los pueblos a partir de su historicidad. Para 
Eisenstein: "Una palabra concreta (una denotación) junto a una palabra concreta da por resultado un concepto abstracto -como sucede en el chino y el japonés, en donde un ideograma material puede indicar un resultado trascendental (conceptual)" (52). En este caso, el empleo que se da en los primeros planos de los niños, permite alimentar un montaje basado en la rítmica de asociaciones, donde el rostro trasunta su condición metafórica para acercarse al interés político por instalar como discurso la idea de la belleza relacionada a la condición de clase y, a la vez, alternándolo con los retazos del mimbre, asocia por medio del contrapunto, la condición humana al trabajo artesanal. Por lo mismo, el tratamiento de los movimientos de cámara en "Mimbre" se orquesta en sincronía con un montaje que deja ver un mundo entrañable en su simpleza, pero paradojalmente muy sofisticado en su construcción.

La música que compone Violeta Parra para la película, que ya ha sido abordada en algunas investigaciones (Corro et al., 2007; Guerrero y Vuskovic, 2018), acentúa la indagación sobre la subjetividad popular que intenta desplegar Bravo. Sin bien este análisis se centra en la visualidad de la película, cabe señalar que la intención de Bravo coincide con las de Parra, en cuanto se busca desplazar las materialidades que ocupa una expresión artística moderna que se vincula al mundo popular. El desborde de la música folclórica lleva a que Violeta Parra indague en otros modelos, tales como la música para ballet -- "El Gavilán"--o la música docta- "Anticueca \#1"-, que reúnen en un disco póstumo "Composiciones para guitarra" (1957), posiblemente el más experimental de toda su producción, pero también, en la realización de un programa radial junto a Ricardo García y Raúl Aicardi ${ }^{7}$. Componer música incidental para cine, como en "Mimbre", forma parte de estas tensiones que se producen entre modernidad y tradición y donde el arte popular busca no ser instrumentalizado, sino ser un material desde el cual reorientar la pregunta sobre la pertinencia de las expresiones vanguardistas de un arte con raigambre local.

\section{Conclusiones}

El trabajo de Sergio Bravo no solo resulta rupturista en la forma, sino en la conciencia política del rol de las imágenes en un proceso que asume la construcción de un lenguaje propio en un periodo que evidencia aperturas hacia el arte popular. Por ello, el objetivo del presente artículo es indagar en lecturas respecto a cómo opera la narración en torno a un sujeto urbano fuertemente enraizado a la cultura campesina, y donde Bravo sitúa el trabajo manufacturado del cineasta de manera horizontal al de "Manzanito", aun cuando proviene de un contexto ilustrado universitario que, durante este periodo, comienza a pensar las expresiones populares como un campo de estudio y de acción. "Mimbre" es contemporáneo a la realización del "I Congreso Nacional de Poetas y Cantores Populares" (1954) o el disco "Aires Tradicionales y Folklóricos de Chile" (1944), ambos con apoyo de la Universidad de Chile y que median entre las expresiones vernáculas y la apertura de las instituciones educativas tradicionales a las expresiones populares. Así, "Mimbre" mezcla un medio masivo y popular, como el cine, con una expresión tradicional, como la artesanía.

El relato visual en "Mimbre" se constituye en base a los fragmentos que provocan, de manera audaz, la reconfiguración de un todo, en este caso el mundo de un artesano, su taller y su oficio. Gracias a la construcción visual de un espacio íntimo abstracto, como el taller, emerge una alegoría de la territorialidad cotidiana en los sujetos populares. La elocuencia de los movimientos que provoca el artesano mientras trabaja va de la mano con una construcción visual que asemeja una coreografía o sinfonía visual, que multiplica las posibilidades formales de un entorno regido por el silencio, la intimidad y la concentración de este artesano. La idea de una luminosidad

7 Ver: Stambuck, Patricia y Bravo, Patricia. "Violeta Parra. El canto de todos”. Pehuén, 2011. 
HORTA. L • La construcción estética del sujeto popular en el documental "Mimbre" (1957) de Sergio Bravo

particular parece entrelazarse con la musicalidad atonal de Violeta Parra, la que deambula en la misma forma que lo hace la cámara entre las varas de mimbre, generando una sensación serpenteante de acercamiento a la realidad. En este sentido, en palabras de Deleuze "El montaje es esa operación que recae sobre las imágenes-movimiento para desprender de ellas el todo, la idea, es decir la imagen del tiempo" (Deleuze 51). En relación con esto, el empleo del tiempo que propone Bravo parece suspender el instante de la creación, sugiriendo una narración particular de la temporalidad del sujeto popular, basándose en el flujo de fragmentos que abordan la relación de las identidades culturales como un problema estético en que volúmenes y la profundidad de campo son protagonistas. El carácter simbólico del cuerpo fragmentado - las manos y el rostro de "Manzanito"- es una construcción que hace referencia permanente a la plasticidad que encierra el hombre y su práctica, invisible y tradicional como la artesanía, rasgo que emerge entre luces y sombras provocadas por una dureza que también aparece en las texturas rugosas de las paredes de adobe o en la piel del artesano ${ }^{8}$. Los momentos fragmentados permiten leer una relación del significado y la experiencia, lo cual expone una clara vindicación política en la puesta en escena, al exaltar el trabajo humano y artesanal como elemento retórico y discursivo que adhiere a las relaciones que plantean distintos cines de vanguardia, y que luego lo harán los Nuevos Cines.

"Mimbre" desarrolla una idea cinematográfica bastante simple basada en el retrato de lo cotidiano: el artesano en su taller. Pero esa premisa no puede sino completarse con el ejercicio elocuente dado en los recursos estéticos del mundo popular, lo cual pone en crisis el sentido de representación existente en el cine chileno de aquel periodo, no solo al prescindir de una puesta en escena, sino también por relevar, como gesto político, una práctica popular y su trabajo colindante. El carácter de proximidad con los sujetos populares, que en la película se grafica con el empleo de la música y el uso del primer plano como recurso expresivo, devela un interés por captar una luz propia de Chile, que alude a una mirada particular sobre el tema de lo popular. En ese aspecto, se enlaza con una idea planteada por el cineasta Raúl Ruiz, quien entrevistado por el periodista Ascanio Cavallo, intenta relacionar la luz cinematográfica con la identidad chilena: "Fíjate que estamos en invierno, y la luz es casi de verano. Recién acabo de medirla: 6.8 a 8, con partes en 11. En el verano, no hablemos: hay que poner sándwiches de filtros. Peor que Argelia. Y si no haces eso, tienes una parte quemada y una negra. El alma chilena es un poco así, ¿no?” (Cavallo 182).

La posibilidad del trabajo popular estetizado, de la misma forma que las exploraciones que realiza en el periodo la cantautora Violeta Parra, plantean una nueva forma de narrar la realidad de una clase social por medio de la poesía visual. Indudablemente, Sergio Bravo no trata de realizar con "Mimbre" un documental sobre la práctica artesanal, sino que de extrapolar las estrategias de montaje y fotografía que aludan específicamente a un retrato del hombre popular, cuyo trabajo táctil se homologa a la praxis del cine artesanal. La humildad de un tratamiento visual que carece del artificio del cine industrial parece ir en sincronía con la manera en que el artesano ejerce su oficio en un marco social que da cuenta de un proceso minuciosamente direccionado hacia la documentación de una atmósfera. Finalmente, la película trata de decir aquello que el lenguaje cinematográfico imperante en aquellos años ni siquiera consignaba dentro de sus contenidos y se vale de una serie de recursos que, independiente a las precariedades técnicas con las que contaba Sergio Bravo en el minuto de realizar esta película o la espectacularidad actual que revista la participación de Violeta Parra en la banda sonora, desborda la condición industrial del cine chileno de los años cincuenta y proyecta, hasta nuestros días, una película abiertamente de ensayo que, al

${ }^{8}$ La relación entre luz natural y un material de construcción como el adobe, también puede constatarse en una película chilena previa, El húsar de la muerte (Pedro Sienna, 1925). 
romper los esquemas de su época, abre también una reflexión visual sobre la naturaleza de la imagen cinematográfica chilena.

\section{Bibliografía}

Anderson, Benedict. Comunidades imaginadas. Ciudad de México, México: Fondo de Cultura Económica, 1993. Impreso.

Aumont, Jacques. El ojo interminable. Barcelona: Paidós, 1997.Impreso.

---. Jacques. El rostro en el cine. Barcelona: Paidós, 1998. Impreso.

Bachelard, Gastón. La poética del espacio. México: Fondo de Cultura Económica, 1965. Impreso.

Bravo Ramos, Sergio. Reiterando afanes. Santiago: Autoedición, 2019. Impreso

Cavallo, Ascanio, "Conversación con Raúl Ruiz: la "summa" de Chile" (2001) en Cuneo, Bruno. Ruiz. Entrevistas escogidas - filmografía comentada. Santiago, Chile: Ediciones Universidad Diego Portales, 2013. Impreso.

Corro Pemjean, Pablo. Sergio Bravo y tendencias del montaje. Aisthesis. Mar.2010.Web.18 mar.2020.

Deleuze, Gilles. La imagen-Tiempo. Buenos Aires: Paidós, 2016. Impreso.

---. Gilles. La imagen-Movimiento. Buenos Aires: Paidós, 2018. Impreso.

Eisenstein, Sergei. El sentido del cine. Ciudad de México, México: Siglo XXI Editores, 1974. Impreso.

---. Sergei. La forma del cine. Ciudad de México, México: Siglo XXI Editores, 2017. Impreso

Guerrero, Claudio y Alekos Vuskovic. La música del Nuevo Cine chileno. Santiago: Cuarto Propio, 2018. Impreso.

Lago, Tomás. Arte popular chileno. Santiago, Chile: Editorial Universitaria, 1997. Impreso

Mouesca, Jacqueline. Plano Secuencia de la memoria de Chile. Santiago: Ediciones Del Litoral. 1988. Impreso.

---. Jacqueline. "Sergio Bravo, pionero del documental en Chile". Araucaria de Chile, n³7, Madrid. 1987. Impreso.

Muñoz, Diego. Antología de 5 poetas populares. Santiago: Ediciones Tácitas, 2017.

Ossa Coo, Carlos. Historia del cine chileno. Santiago: Ediciones Quimantú, 1971. Impreso

Ossa Swears, Carlos. La semejanza perdida. Santiago: Ediciones Metales Pesados, 2009. Impreso

Ossandón, Carlos y Santa Cruz, Eduardo. El estallido de las formas. Chile en los albores de la “cultura de masas". Santiago: Lom Ediciones, 2005.

Ruffinelli, Jorge. América Latina en 130 documentales. Santiago: Uqbar Editores, 2012.

Stambuck, Patricia y Patricia Bravo. Violeta Parra. El canto de todos. Santiago: Pehuén, 2011.

Stange, Hans y Salinas, Claudio. Historia del cine experimental de la Universidad de Chile 19571973. Santiago: Uqbar Editores, 2008.

Talesnik, Daniel. Tibor Weiner y su rol en la reforma: una re-introducción. Revista de Arquitectura. Mar.2006.Web.18 mar.2020

Torres, Rodrigo (Ed.) Aires tradicionales y folklóricos de Chile. Santiago: Facultad de Artes Universidad de Chile. 2005. Impreso.

Vega, Alicia. Itinerario del Cine Documental Chileno. Santiago: Ediciones Universidad Alberto Hurtado. 2006. Impreso.

Vertov, Dziga. El cine ojo. Bilbao: Editorial Fundamentos. 1973. Impreso. 
HORTA. L • La construcción estética del sujeto popular en el documental "Mimbre" (1957) de Sergio Bravo

\section{Filmografía}

A phantasy in colors. Dir. Norman McLaren. 1949.

Berlín, sinfonía de una gran ciudad. Dir. Walther Ruttman,1927.

Blinkity Blank. Dir. Norman McLaren. 1955.

Corral. Dir. Colin Low, 1954.

Mimbre. Dir. Sergio Bravo, 1957.

Spooky sports. Dir.Norman Mc Laren, 1940.

Recibido: 15 de junio de 2020.

Aceptado: 10 de julio de 2020. 